\title{
A Comparative Analysis of Fraction Addition and Subtraction Contents in the Mathematics Textbooks in the U.S. and South Korea
}

\author{
Sunghwan Hwang*a, Sheunghyun Yeob, Taekwon Son ${ }^{\mathrm{c}}$
}

$\begin{array}{ll}\text { Received } & : \text { 16 January } 2021 \\ \text { Revised } & : \text { 2 March } 2021 \\ \text { Accepted } & : \text { 29 March } 2021 \\ \text { DOI } & : 10.26822 / \text { iejee.2021.208 }\end{array}$

Corresponding author: Sunghwan Hwang, Department of Elementary Mathematics Education, Seoul National University of Education, Seoul, South Korea

Telephone number: +82-2-3475-2114

E-mail: ihwang413@gmail.com

ORCID: https://orcid.org/0000-0001-8212-6368

bSheunghyun Yeo, Department of Curriculum and Instruction, College of Education, The University of Alabama, Tuscaloosa, Alabama, U.S.

E-mail: syeo@ua.edu

ORCID: https://orcid.org/0000-0002-8877-1576

'Taekwon Son, Department of Mathematics Education, Korea National University of Education, Cheungju, Chungcheongbuk-do, South Korea E-mail: sontaekwon7@gmail.com

ORCID: https://orcid.org/0000-0003-4497-9188

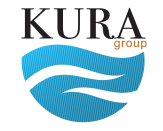

Copyright $(9$

www.iejee.com

ISSN: $1307-9298$

(C) 2021 Published by KURA Education \& Publishing. This is an open access article under the CC BYNC- ND license. (https://creativecommons.org/ licenses/by/4.0/)

\begin{abstract}
Developing textbooks of optimal quality is crucial for enriching the students' learning and understanding. This study examined fraction addition and subtraction problems in the U.S. and South Korean mathematics textbooks according to the types of denominators. In particular, we investigated Everyday Mathematics (EM) and South Korean mathematics (KM) textbooks revised in 2015 and developed an analytic framework encompassing horizontal and vertical dimensions to examine the learning opportunities presented to students by the textbooks. We assessed their topic sequence and frequency of fraction addition and subtraction contents with regard to the former and examined their contextual features, cognitive demands, and mathematical activities with regard to the latter. We observed that EM provided inadequate learning opportunities for fraction subtraction problems, representation problems, and high-order cognitive abilities. However, KM provided more even learning opportunities for fraction addition and subtraction problems, various contextual features, and high and low thinking skills. Moreover, we found that EM emphasized understanding and resolving activities, whereas KM underscored exploring and explaining activities. The findings of this study suggested updating fraction addition and subtraction contents in the U.S., South Korea, and other countries by considering horizontal and vertical dimensions.
\end{abstract}

\section{Keywords: \\ Textbook Analysis; Fraction Addition and Subtraction; Problem Analysis}

\section{Introduction}

The curriculum is designed to achieve educational goals, and textbooks are the most prominent source of its dissemination (Alajmi, 2012; Charalambous et al., 2010; Tan et al., 2018; Yazıcıoğlu \& Pektaş, 2019). As the curriculum is compiled in abstracted language, textbooks facilitate its translation into a readily comprehensible language and activities for the purpose of being utilized 
in actual classroom environments (Stein et al., 2007). For example, a mathematics textbook elucidates mathematical content, problems, pedagogy, and teaching strategies. Therefore, teachers are likely to use textbooks than curriculum for their instruction. According to the Trends in International Mathematics and Science Study (TIMSS), for instance, about $75 \%$ of fourth-grade mathematics teachers use textbooks as their chief teaching resources (Mullis et al., 2012). In this context, researchers conceptualize curriculum, textbooks, teacher's instructions, and student outcome as the intended curriculum, potentially implemented curriculum, implemented curriculum, and attained curriculum, respectively (Valverde et al., 2002).

The quality of a mathematics textbook influences teacher's instructions and student's learning (Stein et al., 2007; Valverde et al., 2002; van den Ham \& Heinze, 2018). Teachers acquire new teaching skills from mathematics textbooks and decide the way to teach mathematics and the concepts to be discussed. Therefore, students are not likely to amass mathematical knowledge, skills, and thinking not presented in the textbooks. For example, the students wholearned mathematics with a high level of cognitive demands problems are likely to develop high-order thinking skills, such as analyzing, reasoning, justifying, and evaluating. Conversely, the students who learned mathematics with a low level of cognitive demands tasks tended to develop low-order thinking skills, such as recalling and computation (Mullis et al., 2012; Tan et al., 2018). As different learning opportunities lead to different mathematical outcomes (Bellens et al., 2020; Hadar, 2017; van den Ham \& Heinze, 2018), developing a high-quality mathematics textbook is a critical issue for educators.

Researchers have analyzed mathematics textbooks across two dimensions, horizontal and vertical (Alajmi, 2012; Charalambous et al., 2010; Li et al., 2009; Özgeldi, \& Aydın, 2021; Son \& Diletti, 2017; Stein et al., 2007). The former focuses on characteristics of contents, including topic placement, allocation of time, development of contents, whereas the latter emphasizes the characteristics of problems, including contextual features, cognitive demands, and problem-solving activities. Li et al. (2009) referred to the horizontal and vertical dimensions as macroanalysis and microanalysis, respectively. Using those analytical frameworks, researchers have examined various mathematical topics, including fractions, integers, algebra, probability, and geometry, to investigate whether they provide students with sufficient opportunities to grasp the topics (Son \& Diletti, 2017).

Among a multitude of mathematical topics, the current study examined fraction addition and subtraction problems in mathematics textbooks.
Accurate understanding of fraction operations is of paramount importance for students' mathematical learning. It not only facilitates understanding other mathematics concepts (e.g., decimal numbers and ratio), but also predicts students' subsequent success in algebra (Martin et al., 2015; Torbeyns et al., 2015). Moreover, the comprehension of fraction operation influences peoples' performance in science, technology, engineering, and mathematics-related jobs, such as construction and computer programming (Handel, 2016). However, studies have reported that most students encounter difficulty in understanding fraction addition and subtraction (Aliustaoğlu et al., 2018; Kara \& Incikabi, 2018; National Council of Teachers of Mathematics [NCTM], 2000). For instance, only the advanced U.S. elementary school students could solve fraction addition and subtraction problems correctly (Lee et al., 2007). Moreover, studies have reported that while some students can solve fraction addition and subtraction problems using appropriate algorithms, they do not completely understand their meaning (Aliustaoğlu et al., 2018; Martin et al., 2015). Given students' misconceptions and difficulties in fraction addition and subtraction problems, researchers have accentuated the importance of developing helpful mathematics textbooks to foster student learning (Charalambous et al., 2010; Son, 2012).

Several studies have been conducted to examine fraction addition and subtraction problems in mathematics textbooks. Charalambous et al. (2010) explored fraction addition and subtraction problems in the mathematics textbooks in Taiwan, Cyprus, and Ireland and Son (2012) investigated the same in the U.S. and South Korean mathematics textbooks. More recently, Yang (2018) examined four fraction operations in mathematics textbooks in Finland and Taiwan. These studies have reported that in comparison to mathematics textbooks in Asian countries, textbooks in Western countries included more problems with symbolic representation (Son, 2012; Yang, 2018). Furthermore, Asian mathematics textbooks chiefly included high cognitive demanding problems, whereas Western mathematics textbooks predominantly comprised low cognitive demanding problems (Charalambous et al., 2010). Although these studies provide new insights into how to design fraction addition and subtraction problems from the international perspective, they examined fraction operation problems without considering the types of denominator.

However, the student's problem-solving process in fraction addition and subtraction problems are different whether the denominator is like or unlike (Aliustaoğlu et al., 2018; Kara \& Incikabi, 2018; NCTM, 2000; Torbeyns et al., 2015). In like denominator (LD) problems, students do not need to be concerned about the denominators and are expected to simply 
add the numerators, whereas in unlike denominator (UD) problems, students are required to find a common denominator for equalization before adding numerators, such as $1 / 2+2 / 3=3 / 6+4 / 6$. Therefore, mathematical knowledge and skills for solving LD and UD problems are different, even though they are both fraction addition and subtraction problems.

Textbook analysis should focus on what learning opportunities are presented to the students according to the types of problems because students become aware of essential aspects of mathematical learning by solving questions in the textbooks (Hadar, 2017; Li et al., 2009). However, there are unanswered questions about how mathematics textbooks present fraction addition and subtraction problems according to the types of denominator. Therefore, the primary objective of this study was to examine what learning opportunities are presented to students for solving LD and UD problems and to gain insights into how to revise the existing fraction addition and subtraction content in textbooks. To accomplish this goal, we selected differentU.S. and South Korean mathematics textbooks. The U.S. textbooks and educational system, as a global benchmark, have been selected and analyzed by several researchers for global comparisons (Son \& Diletti, 2017). Moreover, South Korean students have continuously manifested outstanding performances in international-level tests, such as TIMSS (Mullis et al., 2020). Analyzing mathematics textbooks in the U.S. and South Korea would prospectively contribute to the development of fraction addition and subtraction textbooks and students' understanding of them. The research questions are as following:

1. In the context of horizontal dimension, what are the differences in topic sequence and frequency of fraction addition and subtraction problems between the mathematics textbooks in the U.S. and South Korea?

2. In the context of vertical dimension, what are the differences in contextual features, cognitive demands, and problem-solving activities of fraction addition and subtraction problems between the mathematics textbooks in the U.S. and South Korea?

\section{Methods}

\section{Textbook Selection}

There is no particular national mathematics textbook in the U.S. and schools utilize various types of mathematics textbooks considering student's ability and school context. We used Everyday Mathematics 4th edition (EM; University of Chicago School Mathematics Project, 2015) for comparison with South Korean mathematics textbook (KM). The reason for such selection is that EM is supported by the National Science Foundation and is one of the three most frequently used elementary mathematics textbooks in the U.S. (Malzahn, 2013). Unlike the U.S., South Korean educational system is centralized. All elementary textbooks are developed and published by its Ministry of Education. Therefore, there is only one national elementary mathematics textbook series in South Korea. The latest version of KM was revised in 2015 (Ministry of Education, 2015), which was chosen for this study. Both EM and KM introduced fraction addition and subtraction in grades 4 and 5. Thus, we examined fraction addition and subtraction problems in students' textbooks and supplementary materials (e.g., student workbooks) at these two grade levels.

\section{Analytical Framework}

Researchers have reported that both horizontal and vertical features of a textbook affect students' mathematical learning (Hadar, 2017; Stein et al., 2007). Therefore, we developed an analytical framework across the two dimensions based on several previous studies (Alajmi, 2012; Charalambous et al., 2010; Li et al., 2009; Son, 2012; Stein et al., 2007; Tan et al., 2018). Regarding the horizontal analysis, we examined the topic sequence and frequency (i.e., allocation of the topic). Furthermore, regarding the vertical analysis, we examined the contextual features, cognitive demands, and problem-solving activities (see Table 1). In the following, we explain specifically the analytical framework.

Topic Sequence and Frequency. We first examined the sequence of fraction addition and subtraction lessons (Charalambous et al., 2010; Son, 2012). As each lesson contained a unique type of mathematical algorithm, it was classified based on two criteria: (a) types of denominator (i.e., LD and UD) and (b) types of operation (i.e., addition, subtraction, and both). While some lessons contained operation with natural numbers, we only focused on fraction operation. For example, a lesson introducing $c-\frac{b}{a}-d \frac{e}{a}$ algorithm was classified as LD and subtraction lesson. Six types of topics existed in textbooks, including three topics for LD $\left(\frac{b}{a}+\frac{c}{a}, \frac{b}{a}-\frac{c}{a}, \frac{b}{a}+\frac{c}{a}-\frac{d}{a}\right)$ and three topics for UD $\left(\frac{b}{a}+\frac{d}{c}, \frac{b}{a}-\frac{d}{c}, \frac{b}{a}+\frac{d}{c}-\frac{f}{e}\right)$. Subsequently, we counted the number of individual type of lessons to examine topic frequency. This process enabled us to understand which textbooks focus more on what types of fraction addition and subtraction problems.

Contextual Features. Contextual features refer to how the mathematical problems were illustrated in textbooks. Various contextual features help students think about diverse problem-solving contexts and strategies (Alajmi, 2012; Tan et al., 2018). In particular, representations help students develop accurate understanding of fraction concepts and operations 
Table 1

Analytical Framework for Fraction Addition and Subtraction Problems

\begin{tabular}{|c|c|c|}
\hline Dimension & Component of analysis & Category \\
\hline Horizontal & Topic sequence and frequency & $\begin{array}{l}\text { LD problems } \\
\text {-Addition, Subtraction, Both } \\
\text { UD problems } \\
\text {-Addition, Subtraction, Both }\end{array}$ \\
\hline \multirow{3}{*}{ Vertical } & Contextual features & $\begin{array}{l}\text { Symbolic } \\
\text { Simple word } \\
\text { Word with representation } \\
\text { Word with story }\end{array}$ \\
\hline & Cognitive demands & $\begin{array}{l}\text { Memorization } \\
\text { Procedures without connections } \\
\text { Procedures with connections }\end{array}$ \\
\hline & Problem-solving activities & $\begin{array}{l}\text { Understanding } \\
\text { Estimating } \\
\text { Exploring } \\
\text { Resolving } \\
\text { Explaining }\end{array}$ \\
\hline
\end{tabular}

Note. LD and UD refer to like denominator and unlike denominator, respectively.

(NCTM, 2000). Yang (2018) suggested two criteria for contextual features, including contextualized and noncontextualized (e.g., purely mathematical problems). However, from the pilot analysis, we found that two criteria were not enough to classify all mathematical problems. Therefore, we developed our own framework built on previous studies (e.g., Alajmi, 2012). The developed framework consisted of four elements: symbolic, simple word, word with representation, and word with story problem. The symbolic problem refers to the problems with mathematical symbols and notations and the simple world problem refers to the problems with simple sentences. These two types of problems do not include any contextualization. The word with representation problem refers to the problems with representation, such as figures and number lines. The word with story problem refers to the problems with real-life context. Table 2 encapsulates instances of each type of contextual feature.

Cognitive Demands. Even though when the problems utilize the same contextual feature, the level of cognitive demand might be different. For example, simple word problems can be designed to recall a basic fact or property as low-level thinking (e.g., how many $\frac{1}{4} \sin \frac{3}{4}$ ?) or to explain problem-solving strategies as high-level thinking (e.g., solve $\frac{3}{5}+\frac{4}{5}$ on the number line and explain the way to solve it). Therefore, it is crucial to analyze problems further in terms of the cognitive demand. Cognitive demands indicate the level of thinking required when students are solving problems (Son \& Diletti, 2017; Stein et al., 2000). While some researchers have used two levels of cognitive demands, such as high or low cognitive demands, for analyzing mathematics textbooks (e.g., Son \& Diletti, 2017), the four levels of cognitive demand proposed by Stein et al. (2000) are most extensively used by researchers (Charalambous et al., 2010; Tan et al., 2018). The four levels comprise memorization, procedures without connections, procedures with connections, and doing mathematics. The first two levels are related to low levels of cognitive demands. Memorization refers to the problems asking students to recall previously learned facts, formulas, or definitions. Procedures without connections refer to problems asking students to use algorithms (i.e., procedural knowledge) to solve problems. The last two levels are related to high levels of cognitive demands. Procedures with connections expect students to utilize their deeper understanding of mathematical concepts when solving problems, although they use a certain algorithm. Doing mathematics encompasses the problems that expect the students to use complex and non-algorithmic thinking. In addition, this level requires the students to understand the nature of mathematical concepts through self-monitoring. We decided to use the first three levels of cognitive demands for this study, because the last level, doing mathematics, is not exhaustively presented in elementary mathematics textbooks (Charalambous et al., 2010). Table 3 illustrates examples of the three types of cognitive demands.

Problem-Solving Activities. A mathematical problem entails several mathematical activities to guide students' mathematical investigation. Pólya (1945) proposed four mathematical activities for solving a problem, including understanding the problem, devising a plan, carrying out the plan, and looking back at the result. Similarly, current mathematics textbooks propose various problem-solving activities for solving a complex problem, such as estimating, exploring, resolving, and explaining (e.g., Gracin, 2018; NCTM, 2000). Therefore, we developed five categorizations for analyzing problem-solving activities in textbooks based on the previous studies: understanding, estimating, exploring, resolving, and explaining. It shall be remarked that not all problems in textbooks contain these five types of activities (Gracin, 2018; Son et al., 2020). Understanding refers to making sense of the information, such as number, equation, and figure, given in a problem. Estimating 
refers to estimating answer or quantity of a problem or estimating problem-solving strategies. Exploring refers to exploring answer of a problem by employing the suggested information. Resolving refers to finding and deciding an answer of a problem. Explaining refers to describing the problem-solving strategies and rationale behind an answer to justify their reasoning. Figure 1 illustrates an example of each type of problemsolving activity.

\section{Figure 1}

Example of Each Type of Problem-Solving Activity (from KM 4th, p. 16, Translated by Authors)

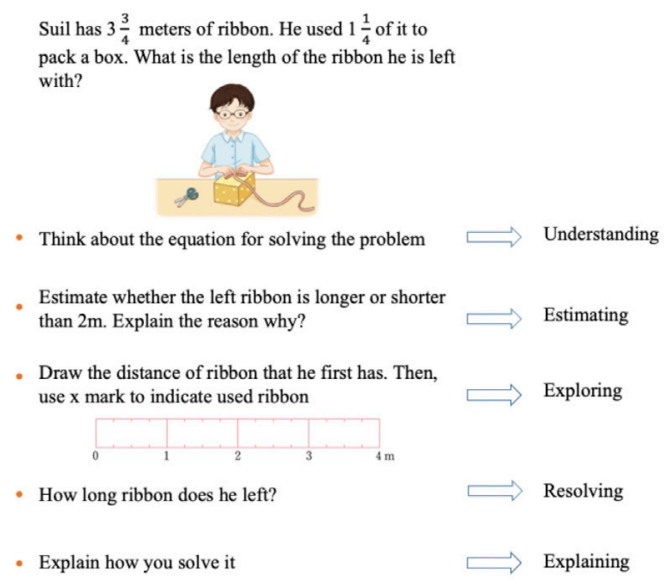

\section{Coding and Reliability}

All the problems in EM and KM were coded by two authors, who independently coded $20 \%$ of the examples (130 cases) across the horizontal and vertical dimensions and subsequently compared their coding to the problems. The inter-coder reliability was calculated using Cohen's Kappa coefficient and its value was .74. The two coders met and resolved any discrepancies through discussion. After clarifying categorization of coding system, they again coded $40 \%$ of the examples (260 cases), including $20 \%$ of examples used for the first coding step. The value of Cohen's Kappa coefficient was found to be .93, revealing a substantial agreement between the two researchers (Agresti, 2018). Then, each author coded the remaining $30 \%$ of the examples, respectively.

\section{Data Analysis}

We first examined the topic sequence and frequency at the horizontal dimension. At this stage, we analyzed the lesson title and main mathematical algorithm discussed in each lesson. Second, at the vertical dimension, we assessed the context features, cognitive demands, problem-solving activities of individual fraction addition and subtraction problems. Note that we separately coded and counted LD and UD problems. A total of 663 problems from EM and KM were examined. Of the 663 problems, however, only 180 problems were investigated for problem-solving activities because other problems did not include specific problem-solving activities. Furthermore, we implemented chi-square tests or Fisher's exact tests to examine the statistical differences between EM and KM. We employed SPSS 21.0 for chi-square tests and astatsa.com, a web- based statistical calculator, for Fisher's exact tests (Vasavada, 2016). Fisher's exact tests were performed when $20 \%$ of the expected values were smaller than five (Agresti, 2018). We used an alpha level of .05 to examine the statistical significance of the results.

\section{Results}

\section{Topics Sequence and Frequency}

The number of lessons for LD and UD was similar for EM and KM. As depicted in Table 4, EM had nine lessons for LD and seven for UD, and KM had nine lessons each for both LD and UD. However, the topic sequence and frequency were observed to be different. EM

Table 2

Categorization of Contextual Features (from KM 4 ${ }^{\text {th }}$, Translated by Author)

\begin{tabular}{|c|c|}
\hline Type & Example \\
\hline Symbolic & $\begin{array}{ll}\text { Find the sum (a) } \frac{1}{4}+\frac{2}{4} & \text { (b) } \frac{3}{6}+\frac{2}{6}\end{array}$ \\
\hline Simple word & $\begin{array}{l}\text { Find two proper fractions satisfying the following conditions. } \\
\text { (a) The denominators of them are } 6 \text {. } \\
\text { (b) The sum and difference of them are } \frac{5}{6} \text { and } \frac{3}{6^{\prime}} \text { respectively. }\end{array}$ \\
\hline $\begin{array}{l}\text { Word with } \\
\text { representation }\end{array}$ & Display $\frac{3}{4}-\frac{1}{4}$ on the square below and find the difference. \\
\hline Word with story & $\begin{array}{l}\text { Suil has } 3 \frac{3}{4} \text { meters of ribbons. He used } 1 \frac{1}{4} \text { of it to pack a box. How many } \\
\text { ribbons is he left with? }\end{array}$ \\
\hline
\end{tabular}


Table 3

Categorization of Cognitive Demands (from EM $4^{\text {th }}$ )

\begin{tabular}{ll}
\hline Type & Write an equation to show the fraction as the sum of unit fractions \\
Memorization & (a) $\frac{4}{12}=$ \\
\hline $\begin{array}{l}\text { Procedures without } \\
\text { connections }\end{array}$ & $\begin{array}{l}\text { On Sunday, Tom ran } \frac{3}{9} \text { of a mile more than Paul. Pan ran } \frac{7}{9} \text { of a mile. How far did Tom run? } \\
\text { Write number model with an unknown variable. }\end{array}$ \\
\hline $\begin{array}{l}\text { Procedures with } \\
\text { connections }\end{array}$ & Decompose $\frac{5}{8}$ into a sum of fraction with the same denominator in three ways. \\
\hline
\end{tabular}

introduced both LD and UD problems simultaneously in a single unit, although grades 4 and 5 focused more on LD and UD problems, respectively (see Table 5). For instance, EM introduced seven lessons addressing fraction with LD problems and two lessons addressing fraction with UD problems at grade 4 (grade 4, lessons 5.4 and 5.5). Moreover, prior to introducing fraction addition at grade 4, EM addressed fraction decomposition and composition (e.g., $\frac{b}{a}=\frac{c}{a}+\frac{d}{a}$ ). The following lessons are extended to adding fractions with UD (e.g., $\left.\frac{b}{10}+\frac{c}{100}\right)$. Likewise, in grade 5, EM first introduced fraction addition and subtraction with LD that students already learned in the previous year. Then, the textbook introduced fraction addition and subtraction with UD. Because some lessons were designed to check students' understanding of previously learned algorithms, fraction addition and subtraction problems were not evenly distributed. Of the 16 lessons, lessons 11, 3, and 2 were related to addition, subtraction, and both, respectively (see Tables 4 and 5). Therefore, students were provided with minimal learning opportunities for practicing fraction subtraction problems. In particular, there was only one fraction subtraction with UD lesson (grade 5, lesson 5.4).

\section{Table 4}

Topic Frequency of Fraction Addition and Subtraction Problems in EM and KM

\begin{tabular}{|c|c|c|c|c|c|}
\hline \multirow{3}{*}{ Denominator } & \multirow{3}{*}{ Operation } & \multicolumn{4}{|c|}{ Frequency } \\
\hline & & \multicolumn{3}{|c|}{ EM } & \multirow{2}{*}{$\begin{array}{r}\mathrm{KM} \\
\text { Grade } \\
5\end{array}$} \\
\hline & & $\begin{array}{r}\text { Grade } \\
4\end{array}$ & $\begin{array}{r}\text { Grade } \\
5\end{array}$ & $\begin{array}{r}\text { Grade } \\
4\end{array}$ & \\
\hline \multirow{3}{*}{ LD } & Addition & 5 & & 2 & \\
\hline & Subtraction & 2 & & 5 & \\
\hline & Both & & 2 & 2 & \\
\hline \multirow{3}{*}{ UD } & Addition & 2 & 4 & & 5 \\
\hline & Subtraction & & 1 & & 3 \\
\hline & Both & & & & 1 \\
\hline Total & & 9 & 7 & 9 & 9 \\
\hline
\end{tabular}

Note. Each number indicates the number of lessons addressing the operation.

In contrast to EM, KM had a rigid structure according to the types of denominators (see Table 6). In grades 4 and 5, students only learned about LD and UD problems, respectively. Moreover, although
EM discussed previously learned mathematical algorithms before introducing new algorithms, KM directly introduced new algorithms without repeating the previous ones. Furthermore, unlike EM, the number of addition and subtraction lessons were similar (seven for addition and eight for subtraction). As a result, South Korean students were provided more equal learning opportunities for practicing fraction addition and subtraction, enabling them to learn various fraction problems.

\section{Context Features}

Table 7 displays the distribution of the contextual features on fraction addition and subtraction problems in EM and KM. The chi-square test was used to examine whether the contextual features between EM and KM were significantly different. Regarding the LD problems, the result of the chi-square test $\left(x^{2}[d f\right.$ $=3]=6.427, p=.093$ ) was not statistically significant, implying no significant relationship between the contextual features and textbooks in LD problems and that the distribution of the four types of contextual features were similar between the two textbooks.

However, the chi-square test for UD problems revealed significant differences between EM and KM $\left(x^{2}[d f=3]\right.$ $=50.898, p<.001)$, which indicated that the proportion of the contextual features varied as a function of textbooks. The gap between EM and KM in word with story problem was negligible (4.2\%). However, the gaps in the other contextual features were more than $10 \%$. The largest proportion of contextual features in EM was of symbolic problems (49.1\%), followed by simple word (32.9\%) and word with story problems (18.0\%); there were no word with representation problems (0\%). However, the largest percentage of contextual features in KM was of simple word problems (54.1\%), followed by symbolic (19.5\%), word with story (13.8\%), and word with representation problems (12.6\%). The findings indicate that the students using EM and KM had similar learning experiences in terms of using contextual features in solving LD problems. However, the students using EM might not be provided with any learning opportunities using representations for solving UD problems. Instead, they were expected to focus more on symbolic and simple word UD problems than the students using KM. 


\section{Table 5}

Topic Sequence of Fraction Addition and Subtraction Problems in EM

\begin{tabular}{|c|c|}
\hline EM grade 4 second semester & EM grade 5 second semester \\
\hline $\begin{array}{l}\text { Unit 5. Fraction and mixed-number computation; } \\
\text { measurement } \\
\text { Unit 8. Fraction operations; applications }\end{array}$ & $\begin{array}{l}\text { Unit 3. Fraction concepts, addition, and subtraction } \\
\text { Unit 5. Operations with fractions }\end{array}$ \\
\hline $\begin{array}{l}\text { 5.1 Fraction decomposition }\left(\frac{b}{a}=\frac{c}{a}+\frac{d}{a}\right) \\
\text { 5.2 The whole for fractions }\left(1=\frac{b}{a}+\frac{c}{a}\right)\end{array}$ & $\begin{array}{l}\text { 3.9 Introduction to addition and subtraction of fractions and } \\
\text { mixed numbers }\left(\mathrm{d} \frac{\mathrm{b}}{\mathrm{a}}+\mathrm{e} \frac{\mathrm{c}}{\mathrm{a}}, \mathrm{d} \frac{\mathrm{b}}{\mathrm{a}}-\mathrm{e} \frac{\mathrm{c}}{\mathrm{a}}\right)\end{array}$ \\
\hline 5.3 Adding fractions $\left(\frac{b}{a}+\frac{c}{a}\right)$ & 3.10 Exploring addition of fractions with UD $\left(\frac{b}{a}+\frac{d}{c}\right)$ \\
\hline 5.4 Adding mixed numbers $\left(d \frac{b}{a}+e \frac{c}{a}\right)$ & 3.12 Solving fraction number stories $\left(d \frac{b}{a}+e \frac{c}{a^{\prime}} d \frac{b}{a}-e \frac{c}{a^{\prime}} \frac{b}{a}+\frac{d}{c}\right)$ \\
\hline 5.5 Adding tenths and hundredths $\left(\frac{\mathrm{b}}{10}+\frac{\mathrm{c}}{100}\right)$ & $\begin{array}{l}5.1 \text { Using equivalent fractions to find common denominators } \\
\left(-\underline{b}+\frac{d}{-}\right)\end{array}$ \\
\hline 5.6 Queen Arlene's dilemma $\left(\frac{1}{\mathrm{a}}+\frac{1}{\mathrm{~b}}+\frac{1}{\mathrm{c}}=1\right)$ & 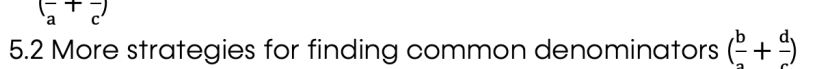 \\
\hline 5.7 Subtracting fractions $\left(\frac{b}{a}-\frac{c}{a^{\prime}} c-\frac{c}{a}\right)$ & 5.3 Addition of fractions and mixed numbers $\left(e \frac{b}{a}+f_{c} \frac{d}{c}\right)$ \\
\hline $\begin{array}{l}\text { 5.8 Subtracting mixed numbers }\left(\frac{d-a}{a}-\frac{e}{a}, c-d \frac{-}{a}\right) \\
\text { 8.6 Fractions and perimeter }\left(\frac{b}{a}+\frac{c}{a}, d \frac{b}{a}+e \frac{c}{a}\right)\end{array}$ & 5.4 Subtraction of fractions and mixed numbers $\left(\frac{\mathrm{b}}{\mathrm{a}}-\frac{\mathrm{d}}{\mathrm{c}^{\prime}} \mathrm{e} \frac{\mathrm{b}}{\mathrm{a}}-\mathrm{f} \frac{\mathrm{d}}{\mathrm{c}}\right)$ \\
\hline
\end{tabular}

\section{Table 6}

Topic Sequence of Fraction Addition and Subtraction Problems in KM

\begin{tabular}{|c|c|}
\hline KM grade 4 second semester & KM grade 5 first semester \\
\hline Unit 1. Fraction addition and subtraction & Unit 5. Fraction addition and subtraction \\
\hline 1.1 Fraction addition $1\left(\frac{b}{a}+\frac{c}{a}\right)$ & 5.1 Fraction addition $1\left(\frac{b}{a}+\frac{d}{c}\right)$ \\
\hline 1.2 Fraction subtraction $1\left(\frac{b}{a}-\frac{c}{a}\right)$ & 5.2 Fraction addition $2\left(\frac{b}{a}+\frac{d}{c}\right)$ \\
\hline 1.3 Fraction addition $2\left(\mathrm{~d}-\frac{\mathrm{b}}{\mathrm{a}}+\mathrm{e} \frac{\mathrm{c}}{\mathrm{c}}\right)$ & 5.3 Fraction addition $3(\mathrm{e}-\mathrm{b}+\mathrm{f}-\mathrm{d})$ \\
\hline 1.4 Fraction subtraction $2\left(d \frac{b}{a}-e \frac{c}{a}\right)$ & 5.4 Fraction subtraction $1\left(\frac{\mathrm{b}}{\mathrm{a}}-\frac{\mathrm{d}}{\mathrm{c}}\right)$ \\
\hline 1.5 Fraction subtraction $3\left(\mathrm{c}-\frac{\mathrm{c}}{3}, \mathrm{c}-\mathrm{d}-\mathrm{b}\right)$ & 5.5 Fraction subtraction $2\left(\mathrm{e}-\frac{\mathrm{b}}{\mathrm{a}}-\mathrm{f}-\mathrm{d}\right)$ \\
\hline 1.6 Fraction subtraction $4\left(\mathrm{~d}-\frac{\mathrm{b}}{\mathrm{a}}-\mathrm{e}-\mathrm{c}\right)$ & 5.6 Fraction subtraction $3\left(\mathrm{e}^{\mathrm{b}}-\mathrm{f}_{\frac{\mathrm{d}}{\mathrm{d}}}^{\mathrm{c}}\right)$ \\
\hline 1.7 Challenging mathematics $\left(c-d \frac{b}{a}+\frac{e}{a}\right)$ & 5.7 Challenging mathematics $\left(e \frac{\vec{b}}{a}+f \frac{d}{c}\right)$ \\
\hline 1.8 Problem solving $\left(d \frac{b}{a}-e \frac{c}{a}, d \frac{b}{a}+e \frac{e}{a}\right)$ & 5.8 Problem solving $\left(e \frac{b}{a}+f \frac{d}{c}, e \frac{b}{a}-f \frac{d}{c}\right)$ \\
\hline 1.9 Exploring mathematics $\left(c-\frac{b}{a}-d^{a}-\right)$ & 5.9 Exploring mathematics $\left(e-\frac{b}{a}+f-\frac{d}{d}\right)$ \\
\hline
\end{tabular}

Table 7

Frequency of Each Contextual Feature

\begin{tabular}{|c|c|c|c|c|c|c|}
\hline & \multicolumn{3}{|c|}{ LD } & \multicolumn{3}{|c|}{ UD } \\
\hline Context feature & EM & $\mathrm{KM}$ & $x^{2}(d f)$ & EM & $\mathrm{KM}$ & $x^{2}(d f)$ \\
\hline Symbolic & 37 (21.0\%) & $43(26.7 \%)$ & \multirow{4}{*}{$\begin{array}{c}6.427(3) \\
(p=.093)\end{array}$} & 82 (49.1\%) & 31 (19.5\%) & \multirow{4}{*}{$50.898(3)^{* * *}$} \\
\hline Simple word & 75 (42.6\%) & 65 (40.3\%) & & 55 (32.9\%) & $86(54.1 \%)$ & \\
\hline $\begin{array}{l}\text { Word with } \\
\text { representation }\end{array}$ & 33 (18.8\%) & $38(23.6 \%)$ & & $0(0.0 \%)$ & 20 (12.6\%) & \\
\hline Word with story & 31 (17.6\%) & 15 (9.4\%) & & 30 (18.0\%) & $22(13.8 \%)$ & \\
\hline Total & 176 & 161 & & 167 & 159 & \\
\hline
\end{tabular}

Note. ${ }^{* * *}$ refers to $<.001$

\section{Cognitive Demand}

Table 8 shows the distribution of the cognitive demand between EM and KM. For LD, the results of the chisquare test showed a significant difference between $\mathrm{EM}$ and $\mathrm{KM}\left(x^{2}[d f=2]=24.016, p<.001\right)$, which implies that the frequency and percentage of cognitive demand in fraction addition and subtraction with LD problems varied as a function of textbooks. Procedures without connections problems were the most frequent type of problem in both the textbooks (65.9\% from EM, $55.3 \%$ from KM). However, EM had more memorization problems $(23.3 \%)$ than procedures with connections problems (10.8\%), whereas KM had more procedures with connections problems (31.6\%) than memorization problems (13.1\%).

Similar to LD problems, UD problems in both the textbooks emphasized procedures without connections problems than the other types of 
Table 8

Frequency of Each Cognitive Demand

\begin{tabular}{|c|c|c|c|c|c|c|}
\hline & & LD & & & UD & \\
\hline Cognitive demand & EM & KM & $x^{2}(d f)$ & EM & $\mathrm{KM}$ & $x^{2}(d f)$ \\
\hline Memorization & $41(23.3 \%)$ & $21(13.1 \%)$ & & $8(4.8 \%)$ & $10(6.3 \%)$ & \\
\hline $\begin{array}{l}\text { Procedures without } \\
\text { connections }\end{array}$ & $116(65.9 \%)$ & 89 (55.3\%) & $24.016(2)^{* * *}$ & $150(89.8 \%)$ & 122 (76.7\%) & $11.915(2)^{* *}$ \\
\hline $\begin{array}{l}\text { Procedures with } \\
\text { connections }\end{array}$ & 19 (10.8\%) & 51 (31.6\%) & & $9(5.4 \%)$ & 27 (17.0\%) & \\
\hline Total & 176 & 161 & & 167 & 158 & \\
\hline
\end{tabular}

problems (89.8\% from EM, 76.7\% from KM). However, the chi-square test showed significant differences between them $\left(x^{2}[d f=2]=11.915, p<.01\right)$, indicating that the distribution of cognitive demand was statistically different between EM and KM. Whereas $5.4 \%$ of problems in EM focused on procedures with connections problems, $17 \%$ of problems in KM were procedures with connections problems. These findings indicate that regardless of the type of denominators, the students using EM are more likely to use low-level thinking for solving fraction addition and subtraction problems than students using KM. In other words, students using EM are provided relatively limited learning opportunities to facilitate high-level thinking than the students using KM.

\section{Problem-Solving Activities}

Table 9 shows the distribution of the problem-solving activities presented in EM and KM. For LD, a Fisher's exact test of the association between problemsolving activities and textbook type was significant ( $p$ < .001), indicating a significant difference between EM and KM with varying problem-solving activities. The largest proportion of problem-solving activities in EM focused on understanding (50\%), followed by exploring (25\%) and resolving (25\%). However, there were no activities for estimating (0\%) and explaining (0\%). By contrast, KM had a more even distribution across the five mathematical activities with each activity having a proportion more than $10 \%$ : exploring (37.9\%), explaining (21.6\%), resolving (18.9\%), estimating (10.8\%), and understanding (10.8\%).

For UD, the test of association between textbooks and problem-solving activities was significant (Fisher's exact test, $p<.001)$. In EM, resolving activities were the most frequent (35.8\%), followed by estimating (28.3\%), understanding (17.0\%) exploring (13.2\%), and explaining (5.7\%). In contrast, KM did not have any resolving activities (0\%) and exploring had the largest proportion (41.2\%), followed by estimating (20.6\%), explaining (20.6\%), and understanding (17.6\%). In summary, the students using KM are more likely to experience exploring and explaining activities for solving fraction addition and subtraction problems than the students using EM.

\section{Discussion}

This study examined EM and KM fraction addition and subtraction problems with regard to the types of denominators. By virtue of categorizing fraction problems according to the types of denominators, we discovered certain differences between EM and KM. For the horizontal dimension, the results demonstrated that there were differences in the topic sequence and frequency between EM and KM. Both textbooks generally introduced LD and UD at grade 4 and grade 5, respectively. Meanwhile, EM has more flexible structure than KM. Some LD and UD lessons in EM were included in subsequent year's textbooks. Moreover, because some lessons were designed to check previously learned algorithms, EM did not provide sufficient lessons for introducing fraction subtraction. Of the 16 lessons, there were only three lessons solely focusing on fraction subtraction. That is, the students using EM were provided minimal learning opportunities for practicing fraction subtraction problems.

In contrast, KM was observed to have a very rigid structure. It did not repeat previously leaned mathematical algorithms; instead, fourth and fifth graders only learned about LD and UD problems at their grade levels. Moreover, lessons on addition (seven) and subtraction (eight) were almost uniformly distributed. As KM did not provide the students with opportunities to learn again the previously learned algorithms, students without a clear understanding of them might encounter difficulties in learning new algorithms. At the expense of it, however, students were provided sufficient time for learning new algorithms, which helped them learn and practice various fraction addition and subtraction problems. Mathematical contents in the textbooks affect students' learning opportunities and mathematics achievement (Hadar, 2017; Stein et al., 2007; van den Ham \& Heinze, 2018). Therefore, EM might provide the students with more opportunities for learning fraction subtractions. Additionally, KM might provide a lesson 
Table 9

Frequency of Each Problem-Solving Activity

\begin{tabular}{|c|c|c|c|c|c|c|}
\hline \multirow[b]{2}{*}{$\begin{array}{l}\text { Problem solving ac- } \\
\text { tivity }\end{array}$} & \multicolumn{2}{|c|}{ LD } & \multicolumn{4}{|c|}{ UD } \\
\hline & EM & KM & $\begin{array}{l}\text { Fisher's } \\
\text { exact Test }\end{array}$ & EM & KM & $\begin{array}{c}\text { Fisher's exact } \\
\text { test }\end{array}$ \\
\hline Understanding & $28(50 \%)$ & $4(10.8 \%)$ & & $9(17.0 \%)$ & $6(17.6 \%)$ & \\
\hline Estimating & $\mathrm{O}(0.0 \%)$ & $4(10.8 \%)$ & & $15(28.3 \%)$ & $7(20.6 \%)$ & \\
\hline Exploring & $14(25.0 \%)$ & $14(37.9 \%)$ & $p<.001$ & $7(13.2 \%)$ & $14(41.2 \%)$ & $p<.001$ \\
\hline Resolving & $14(25.0 \%)$ & $7(18.9 \%)$ & & $19(35.8 \%)$ & $0(0.0 \%)$ & \\
\hline Explaining & $0(0.0 \%)$ & $8(21.6 \%)$ & & $3(5.7 \%)$ & $7(20.6 \%)$ & \\
\hline Total & 56 & 37 & & 53 & 34 & \\
\hline
\end{tabular}

for checking previously learned algorithms to enable students practice them.

To examine the vertical dimension, this study examined the contextual features, cognitive demands, and problem-solving activities in textbooks. First, the findings of this study showed that the four types of contextual features used for LD problems were similar between EM and KM. However, their distribution for UD problems between EM and KM varied significantly. In particular, EM did not contain any word with representation problem for fraction with UD. This result contradicts previous studies that reported mathematics textbooks in Western countries including more problems with symbolic representation (Son, 2012). The differences between the previous studies and the current study might be caused by the fact that South Korean mathematic textbooks were revised in 2015 to include more problems with representations (Ministry of Education, 2015). NCTM (2000) remarked "Representation should be treated as essential elements in supporting students' understanding of mathematical concepts and relationships" (p. 67). In addition, NCTM (2000) found that using various representations improves students' understanding of and operation with fraction addition and subtraction. Therefore, it can be suggested that EM should devote considerable attention to incorporate more representation problems.

Second, the frequency and percentage of the cognitive demand in LD and UD problems varied as a function of textbooks. Procedures without connections problems were the most frequent type in both the textbooks. However, the second largest problems in EM and KM were memorization problems and procedures with connections problems, respectively. This supports a previous study that mathematics textbook in Asian countries included more cognitively challenging problems (Charalambous et al., 2010). As problems in EM required students to use low-order thinking skills for solving problems, they are unlikely to develop a deeper conceptual understanding of fraction addition and subtraction. Conversely, the students using KM were provided more cognitively challenging learning opportunities on fraction addition and subtraction than those using EM. These different learning opportunities may negatively affect students' mathematics outcomes (Hadar, 2017; van den Ham \& Heinze, 2018). Therefore, the author of EM is recommended to update fraction addition and subtraction problems with respect to the cognitive demand.

Third, the results revealed that EM and KM were significantly different regarding the distribution of problem-solving activities. In both LD and UD problems, EM focused more on understanding and resolving, whereas $\mathrm{KM}$ focused more on exploring and explaining. These findings indicate that the students using EM are likely to attend to understanding information presented in a problem and find its solution. However, they were provided relatively less opportunities to not only explore and compare diverse problem-solving strategies, but also explain and justify their findings to peers and teachers than the students using KM. These findings are consonant with Gracin (2018), reporting that mathematics textbooks tend to provide limited range of mathematical activities. As teachers are likely to use problem-solving activities presented in textbooks, students seldom experience other activities not presented in the textbooks (Stein et al., 2007). Therefore, both EM and KM are suggested to be revised to include more evenly the five problemsolving activities.

\section{Conclusion}

Developing high-quality textbooks is cardinal for ensuring students' mathematical learning opportunities and improving their outcomes (Bellens et al., 2020; Hadar, 2017). Existing literature has offered guidance on how to design fraction addition and subtraction problems with regard to horizontal and vertical dimensions (e.g., Son, 2012). However, it did not consider the types of denominators. In this study, we investigated the topic sequence and frequency, contextual features, cognitive demands, and problem-solving activities in EM and KM considering LD and UD problems. Moreover, we implemented chisquare and Fisher's exact tests to examine statistical differences between the textbooks. Although we only examined mathematics textbooks in the U.S. and 


\section{iejee}

South Korea, the findings of the study can provide the groundwork to the textbook developers in other countries for designing future fraction addition and subtraction contents. Moreover, teachers may use mathematics textbooks by considering the horizontal and vertical dimensions of the problems discussed in this study. They may modify their instructions or textbooks to provide the students with adequate learning opportunities.

This study has two limitations. First, we only examined one series of mathematics textbooks in the U.S., although it has different series of mathematics textbooks. Therefore, while EM was one of the three most frequently used elementary mathematics textbooks in the U.S. (Malzahn, 2013), the findings of this study could not be interpreted as characteristics of all the U.S. mathematics textbooks. Second, we did not analyze the use of textbooks by the teachers in classrooms. As teachers may use textbooks in different ways (Stein et al., 2007), we cannot readily assume that characteristics of fraction problems in textbooks directly influence students' learning opportunities. That is, some teachers might not use the content presented in textbooks, and others might introduce content not presented in the textbooks. Therefore, the findings of this study should be interpreted with caution. Given these limitations, we suggest future studies. First, more studies are essential to examine the horizontal and vertical dimensions of fraction addition and subtraction problems by using a series of textbooks. Second, further efforts are required to investigate how teachers and students use mathematics textbooks in classrooms. The findings of these future studies can plausibly ensure students' learning opportunities and improve their mathematics achievement with regard to fraction addition and subtraction.

\section{References}

Agresti, A. (2018). An introduction to categorical data analysis. John Wiley \& Sons. https://doi. org/10.1002/bimj.4710290113

Alajmi, A. H. (2012). How do elementary textbooks address fractions? A review of mathematics textbooks in the USA, Japan, and Kuwait. Educational Studies in Mathematics, 79(2), 239261. https://doi.org/10.1007/s10649-011-9342-1

Aliustaoğlu, F., Tuna, A., \& Biber, A. Ç. (2018). The misconceptions of sixth grade secondary school students on fractions. International Electronic Journal of Elementary Education, 10(5), 591-599. https://doi.org/10.26822/iejee.2018541308
Bellens, K., Van den Noortgate, W., \& Van Damme, J. (2020). The informed choice: Mathematics textbook assessment in light of educational freedom, effectiveness, and improvement in primary education. School Effectiveness and School Improvement, 31(2), 192-211. https://doi.or $\mathrm{g} / 10.1080 / 09243453.2019 .1642215$

Charalambous, C. Y., Delaney, S., Hsu, H. Y., \& Mesa, V. (2010). A comparative analysis of the addition and subtraction of fractions in textbooks from three countries. Mathematical Thinking and Learning, 12(2), 117-151. https://doi. org/10.1080/10986060903460070

Gracin, D. (2018). Requirements in mathematics textbooks: A five-dimensional analysis of textbook exercises and examples. International Journal of Mathematical Education in Science and Technology, 49(7), 1003-1024.

Hadar, L. L. (2017). Opportunities to learn: Mathematics textbooks and students' achievements. Studies in Educational Evaluation, 55, 153-166. https:// doi.org/10.1016/j.stueduc.2017.10.002

Handel, M. J. (2016). What do people do at work? Journal for Labour Market Research, 49(2), 177197. https://doi.org/10.1007/s12651-016-0213-1

Kara, F., \& Incikabi, L. (2018). Sixth grade students' skills of using multiple representations in addition and subtraction operations in fractions. International Electronic Journal of Elementary Education, 10(4), 463-474. https://doi.org/10.26822/ iejee. 2018438137

Lee, J., Grigg, W., \& Dion, G. (2007). The Nation's Report Card: Mathematics 2007 (NCES 2007-494). National Center for Education Statistics, Institute of Education Sciences, U.S. Department of Education. https://doi. org/10.4135/9781412957403.n289

Li, Y., Chen, X., \& An, S. (2009). Conceptualizing and organizing content for teaching and learning in selected Chinese, Japanese and US mathematics textbooks: The case of fraction division. ZDM, 41(6), 809-826. https://doi. org/10.1007/s11858-009-0177-5

Malzahn, K. A. (2013). 2012 national survey of science and mathematics education: Status of elementary school mathematics. Horizon Research. https://doi.org/10.1111/j.1949-8594.1958. tb08086.x 
Martin, T., Petrick Smith, C., Forsgren, N., Aghababyan, A., Janisiewicz, P., \& Baker, S. (2015). Learning fractions by splitting: Using learning analytics to illuminate the development of mathematical understanding. Journal of the Learning Sciences, 24(4), 593-637. https://doi.org/10.1080/ 10508406.2015 .1078244

Ministry of Education. (2015). Korean mathematics curriculum revised in 2015. Ministry of Education.

Mullis, I. V., Martin, M. O., Foy, P., \& Arora, A. (2012). TIMSS 2011 international results in mathematics. Boston College, TIMSS \& PIRLS International Study Center.

Mullis, I. V. S., Martin, M. O., Foy, P., Kelly, D. L., \& Fishbein, B. (2020). TIMSS 2019 international results in mathematics and science. Boston College, TIMSS \& PIRLS International Study Center.

National Council of Teachers of Mathematics. (2000). Principles and standards for school mathematics.

Özgeldi, M., \& Aydın, U. (2021). Identifying competency demands in calculus textbook examples: The case of integrals. International Journal of Science and Mathematics Education, 19(1), 171191. https://doi.org/10.1007/s10763-019-10046-9

Pólya, G. (1945). How to solve it: A new aspect of mathematical method. Princeton University Press. https://doi.org/10.2307/j.ctvc773pk

Son, J. W. (2012). A cross-national comparison of reform curricula in Korea and the US in terms of cognitive complexity: The case of fraction addition and subtraction. ZDM, 44(2), 161-174. https://doi.org/10.1007/s11858-012-0386-1

Son, J. W., \& Diletti, J. (2017) What can we learn from textbook analysis? In Son, J.W., Watanabe, T., \& Lo, J.J.(Eds.), What matters? Research trends in international comparative studies in mathematics education (pp. 3-32). Springer. https://doi.org/10.1007/978-3-319-51187-0_1

Stein, M. K., Remillard, J., \& Smith, M. S. (2007). How curriculum influences student learning. In F. K. Lester (Ed.), Second handbook of research on mathematics teaching and learning (pp. 319369). Information Age Publishing.

Stein, M. K., Smith, M. S., Henningsen, M., \& Silver, E. A. (2000). Implementing standards based mathematics instruction. Teachers College Press.
Son, T. K., Hwang, S. H., \& Yeo, S. H. (2020). An analysis of the 2015 revised curriculum addition and subtraction of fractions in elementary mathematics textbooks. School Mathematics, 22(3), 489-508. DOI : 10.29275/sm.2020.09.22.3.489

Tan, K. J., Ismail, Z., \& Abidin, M. (2018). A comparative analysis on cognitive domain for the Malaysian primary four textbook series. EURASIA Journal of Mathematics, Science and Technology Education, 14(4), 1273-1286. https://doi. org/10.29333/ejmste/82625

Torbeyns, J., Schneider, M., Xin, Z., \& Siegler, R. S. (2015). Bridging the gap: Fraction understanding is central to mathematics achievement in students from three different continents. Learning and Instruction, 37, 5-13. https://doi. org/10.1016/j.learninstruc.2014.03.002

University of Chicago School Mathematics Project. (2015). Everyday Mathematics Student Math Journal (4th ed.). McGraw-Hill Education.

Valverde, G. A., Bianchi, L. J., Wolfe, R. G., Schmidt, W. H., \& Houang, R. T. (2002). According to the book: Using TIMSS to investigate the translation of policy into practice through the world of textbooks. Springer Science \& Business Media. https://doi.org/10.1007/978-94-007-0844-0

van den Ham, A. K., \& Heinze, A. (2018). Does the textbook matter? Longitudinal effects of textbook choice on primary school students' achievement in mathematics. Studies in Educational Evaluation, 59, 133-140. https://doi. org/10.1016/j.stueduc.2018.07.005

Vasavada N. P. (2016). Online web statistical calculators. Vasavada. Retrieved January 02, 2021 from https://astatsa.com.

Yang, D. C. (2018). Study of fractions in elementary mathematics textbooks from Finland and Taiwan. Educational Studies, 44(2), 190-211. https://doi.org/10.1080/03055698.2017.1347493

Yazıcıoğlu, Ö., \& Pektaş, M. (2019). A Comparison of the middle school science programmes in Turkey, Singapore and Kazakhstan. International Electronic Journal of Elementary Education, 11(2), 143-150. https://doi.org/10.26822/ iejee. 2019248588 